\title{
Geometry of the left ventricular outflow tract in fixed subaortic stenosis and intact ventricular septum: An echocardiographic study in children and adults
}

\author{
Reza Barkhordarian, MBBS, MRCS, ${ }^{\mathrm{a}, \mathrm{c}}$ Ding Wen-Hong, MD, ${ }^{\mathrm{b}}$ Wei Li, MD, PhD, ${ }^{\mathrm{b}}$ Manjit Josen, BSc, ${ }^{\mathrm{b}}$
} Michael Henein, MD, PhD, ${ }^{b}$ and Siew Yen Ho, PhD, FRCPath, FESC ${ }^{a}$

From the Departments of Pediatrics, ${ }^{\text {a }}$ Cardiology/Echocardiography, ${ }^{\mathrm{b}}$ and Cardiothoracic Surgery, ${ }^{\mathrm{c}}$ Royal Brompton Hospital and Imperial College, London, United Kingdom.

The Cardiac Morphology Unit at the Royal Brompton Hospital receives funding support from the Royal Brompton and Harefield Charitable Fund

Received for publication Jun 8, 2006; revisions received Aug 3, 2006; accepted for publication Sep 11, 2006

Reprint requests: Reza Barkhordarian, MBBS, MRCS, Department of Paediatrics, Cardiac Morphology Unit, Royal Brompton Hospital, Sydney Street, London SW3 6NP, UK (E-mail: r.barkhordarian@imperial. ac.uk).

J Thorac Cardiovasc Surg 2007;133:196-203 $0022-5223 / \$ 32.00$

Copyright $\odot 2007$ by The American Association for Thoracic Surgery

doi:10.1016/j.jtcvs.2006.09.010
Objective: We compared the echocardiographic geometry of the preoperative and postoperative left ventricular outflow tract in children and adults with isolated fixed subaortic stenosis with age- and weight-matched controls to elucidate whether the geometry can be modified when surgical intervention is performed at a younger age.

Methods: The mitral-aortic valve distance, aortic valve diameter, aorto-left ventricular septal angle, degree of aortic valve dextroposition, aortic valve-subaortic stenosis distance, width of left ventricular outflow tract, left ventricle wall thickness, and septal thickness were determined preoperatively and postoperatively in 21 patients and 21 controls. The measurements were indexed to body surface area. Patients were divided into 3 age groups: group 1 comprised 9 patients aged 1 to 10 years, group 2 comprised 8 patients aged 11 to 20 years, and group 3 comprised 4 patients aged 21 years or more.

Results: Compared with controls, patients had a significantly wider mitral-aortic separation (group $1, P=.003$; group $2, P=.02$ ), a steeper aortoseptal angle (group $1, P=.02$; group $3, P=.03$ ), a smaller left ventricular outflow tract width (group $1, P=.003$; group $2, P=.01$ ), a marked aortic valve dextroposition (groups 1 and 3 ), an increased left ventricle wall thickness (group 1, $P=.03$ ), and an increased septal thickness (group $1, P=.01$ ). There was a significant difference between preoperative and postoperative values in aortoseptal angle and left ventricular outflow tract width in patients up to 10 years of age $(P=.02$ and $P=.01$, respectively).

Conclusions: Hearts with isolated subaortic stenosis have abnormal left ventricular outflow tract geometry that postoperatively showed changes in left ventricular outflow tract width and aortoseptal angle. Compared with controls, the aortoseptal angle does not "normalize" when surgery is performed in older patients, suggesting that left ventricular outflow tract geometry may be remodeled in younger patients.

$\mathrm{F}$ Tixed subaortic stenosis is usually a fibromuscular ring or crescent-like shelf below the aortic valve. The incidence of subaortic stenosis is 0.25 for every 1000 live births. ${ }^{1}$ Accounting for $8 \%$ to $20 \%$ of all forms of left ventricular outflow tract (LVOT) obstruction, ${ }^{2}$ subaortic stenosis is the second most common type of fixed aortic stenosis after valvar aortic stenosis. ${ }^{3-5}$ Morphologic abnormalities of the LVOT and abnormal flow pattern and turbulence have been suggested to lead to proliferation of tissues in the subvalvar region. ${ }^{2,6} \mathrm{~A}$ high recurrence rate after surgical resection of the subvalvar lesion may suggest that residual tissue was left unaltered by surgery. Patients with ventricular septal defects have already been described to be at risk of turbulence and, consequently, subaortic stenosis. ${ }^{3}$ Echocardiography is the current standard diagnostic tool for subaortic stenosis. The aim of this study was to identify abnormal morphologies by echocardiography of the 


\section{Abbreviations and Acronyms \\ BSA = body surface area \\ LVOT $=$ left ventricular outflow tract}

LVOT tract region in children and adults with fixed subaortic stenosis and intact ventricular septum. We also aimed to examine whether surgical resection of the lesion not only relieves the narrowing of the outflow tract but also alters its geometry. Because the timing of surgical intervention remains contentious, ${ }^{3,10,13}$ we explored whether there is any evidence for "remodeling" of the outflow tract in younger patients.

\section{Materials and Methods \\ Patients}

This retrospective study comprised all patients with fixed subaortic stenosis and intact ventricular septum diagnosed by echocardiography at The Royal Brompton Hospital from 2000 to 2005. According to their age at the time of operation, the patients were allocated into 3 groups (1-10 years, 11-20 years, and $>20$ years). There were 21 patients with subaortic stenosis and intact ventricular septum (14 males, 7 females). Nine patients with a median age of 5 years were in group 1, 8 patients with a median age of 12 years were in group 2, and 4 patients with a median age of 38.5 years were in group 3. All patients had subaortic ridge resection only. The diagnosis of fixed subaortic stenosis was based on the demonstration of a localized subvalvar obstruction in the LVOT tract according to the criteria of Weyman and colleagues. ${ }^{7}$ Postoperative echocardiography was carried out within 1 month of surgery.

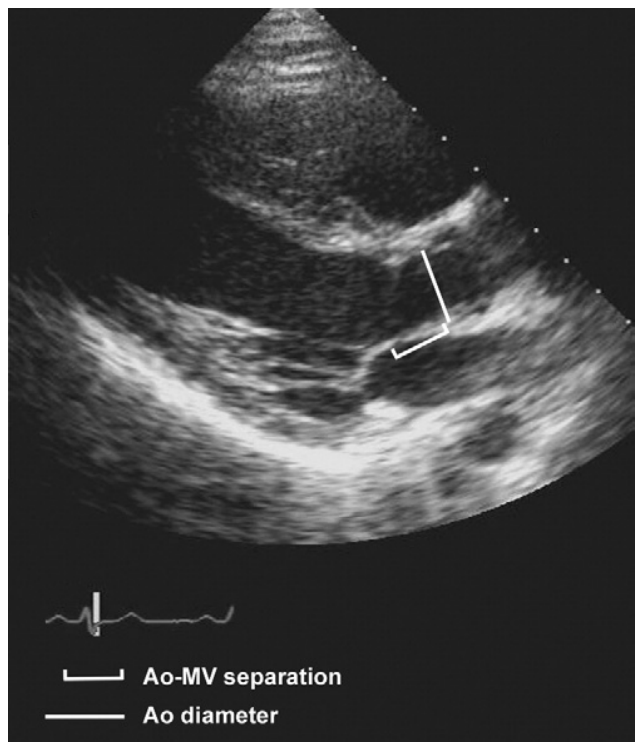

Figure 1. Parasternal long-axis view showing mitral-aortic valve distance and aortic valve diameter. Ao-MV, Aortic-mitral valve.

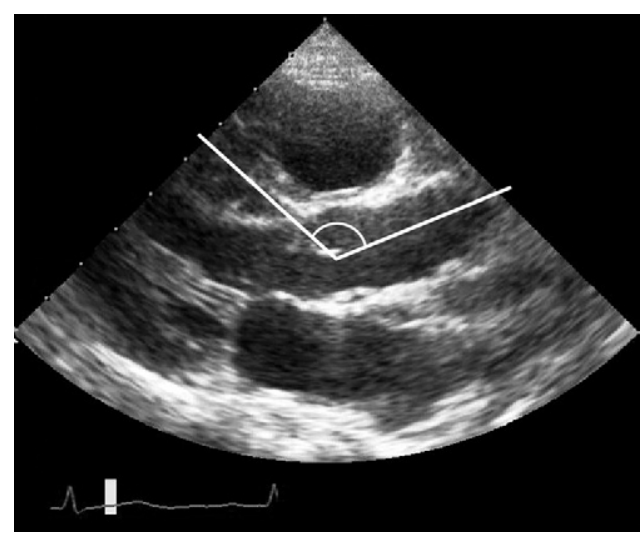

Figure 2. Aortoseptal angle formed by the long axis of the ascending aorta and the plane of the ventricular septum.

Echocardiograms of age-, gender-, and weight-matched healthy volunteers were used as controls.

\section{Echocardiography}

The controls and available preoperative and postoperative echocardiograms were reviewed, and suitable frames were selected for measurements. One observer, blinded from the clinical data, made the measurements on 3 separate occasions and averaged the values. The following measurements were made.

- The mitral-aortic valve distance (Figure 1) in the parasternal long-axis view at systole was measured from the hinge point of the noncoronary aortic valve leaflet to the hinge point of the aortic leaflet (anterior leaflet) of the mitral valve.

- The aortic valve diameter (Figure 1) was measured in the parasternal long-axis view in midsystole between the hinge points of the right coronary and noncoronary aortic leaflets.

- The aortoseptal angle (Figures 2 and 3,A) was measured using a transparent protractor superimposed on the angle formed by the long axis of the ascending aorta and the plane of the ventricular septum according to the method described by Fowles and colleagues. ${ }^{8}$

- The degree of aortic valve dextroposition (Figure 4) was measured from the apical 5- and 2-chamber views in midsystole. This feature was previously described as "aortic override." This was the degree of juxtaposition to the long axis of the ventricular septum and was assessed as normal, mild, or marked when the long axis intercepts the aortic annulus by less than one third, between one third and two thirds, and more than two thirds, respectively.

- The aortic valve and subaortic shelf distance (Figure 5) was measured in end diastole on the parasternal long-axis view from the septal attachment of the ridge to the base of the right aortic leaflet.

- The LVOT width was measured in systole (Figure 5) from the parasternal long axis of the left ventricle from the inner edge of the junction between the posterior aortic wall and 

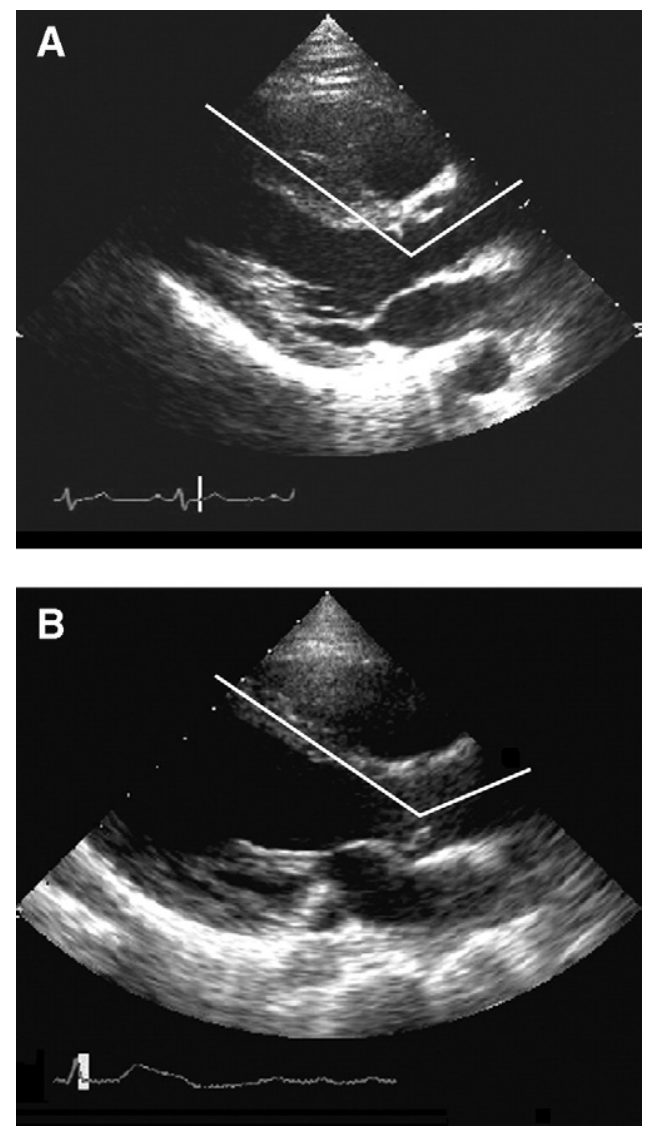

Figure 3. A, Preoperative acute aortoseptal angle formed by the long axis of the ascending aorta and the plane of the ventricular septum in hearts with subaortic stenosis and intact ventricular septum. B, Postresection of the subaortic ridge. The aortoseptal angle as shown is significantly wider than pre-resection, demonstrating the "remodeling" of the LVOT after surgery.

aortic leaflet of the mitral valve and the interventricular septum below the aortic valve.

- The left ventricular posterior wall thickness was measured in diastole using M-mode recordings or parasternal long-axis 2-dimensional images as the distance between the endocardium and the epicardium of the posterior wall.

- The end-diastolic septal thickness was measured using Mmode recordings or long-axis 2-dimensional images.

- The LV dimension was the distance between the septal and posterior endocardium at end diastole and end systole.

- Aortic regurgitation was graded as mild, moderate, or severe using parasternal long-axis view and color Doppler jet diameter according to Frommelt and colleagues. ${ }^{9}$

- The peak LVOT gradient was measured from continuouswave Doppler velocities using a 2- or 5-chamber view and the simplified Bernoulli equation (gradient $=4 \mathrm{~V}^{2}$ ).

The above measurements were indexed to body surface area (BSA) for intergroup comparisons.

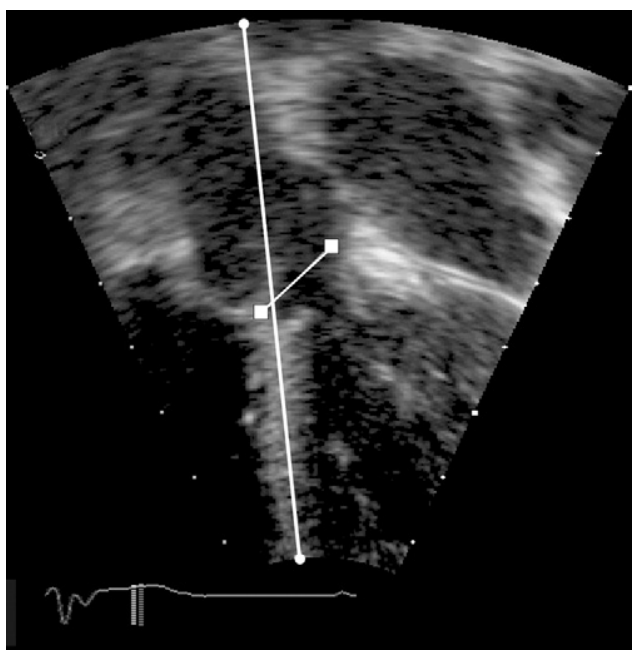

Figure 4. Mild aortic valve dextroposition when the long axis intercepts the aortic annulus by less than one third. This dextroposition is marked in hearts with subaortic stenosis and intact ventricular septum.

\section{Statistics}

The measurements were expressed as the median with an interquartile range (25th-75th percentile). The Mann-Whitney nonparametric test was used to compare each group of patients with its matched controls. The Wilcoxon nonparametric signed-rank test

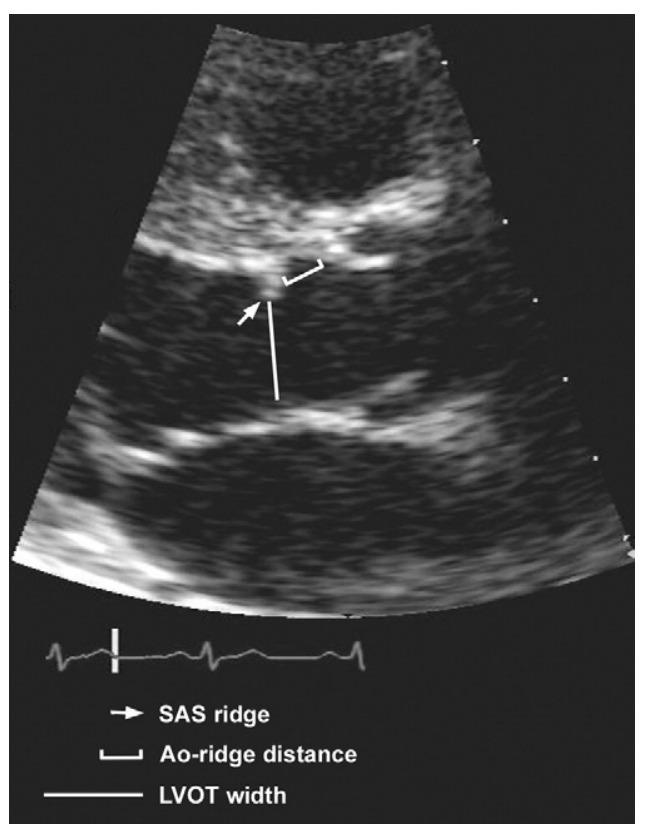

Figure 5. Parasternal long-axis view demonstrating subaortic ridge, width of LVOT, aortic valve, and subaortic stenosis distance. SAS, Subaortic stenosis; Ao, aortic; LVOT, left ventricular outflow tract. 
TABLE 1. Clinical characteristics of the study groups

\begin{tabular}{lccr}
\hline & Group 1 (n= 9) & Group 2 (n= 8) & Group 3 (n= 4) \\
\hline Male/female ratio & $9: 0$ & $5: 3$ & $0: 4$ \\
Median age (y) at operation & $5(4.7-6.2)$ & $12(11.5-14.5)$ & $38.5(32.5-42.5)$ \\
Preoperative echo gradient $(\mathrm{mm} \mathrm{Hg})$ & $70(57.5-84.5)$ & $60(34.7-67.5)$ & $70(44.5-77.5)$ \\
Postoperative echo gradient $(\mathrm{mm} \mathrm{Hg})$ & $13.3(8.9-35.3)$ & $5.4(4.7-13.4)$ & $28.5(21.5-36.5)$ \\
BSA (m) & $0.77(0.75-0.97)$ & $1.39(1.2-1.5)$ & $1.80(1.73-2.0)$ \\
Aortic regurgitation (preoperative) & $6(67 \%)$ & $7(87 \%)$ & $3(75 \%)$ \\
$\quad$ Mild & 5 & 6 & 2 \\
Moderate & 1 & 1 & 1 \\
Severe & 0 & 0 & 0 \\
(postoperative) & $5(55 \%)$ & $4(50 \%)$ & $2(40 \%)$ \\
$\quad$ Mild & 4 & 3 & 1 \\
Moderate & $1(11 \%)$ & $1(12 \%)$ & 0 \\
Severe & 0 & 0 & 0 \\
\hline
\end{tabular}

$B S A$, Body surface area.

was used to compare preoperative and postoperative values in each group. The Kruskal-Wallis nonparametric test was used to compare the different age groups.

\section{Results}

\section{Echocardiographic Measurements}

Table 2 shows the preoperative echocardiographic findings in patients and controls. Significant findings were found in each of the following parameters indexed to BSA:

The mitral-aortic valve distance ${ }_{\mathrm{BSA}}$ in groups 1 and 2 was wider than in the controls $(P=.003$ and $P=.02$, respectively), and the aortoseptal angle in groups 1 and 3 was steeper than in the corresponding controls $(P=.02$ and $P=.03$, respectively).

The LV outflow tract width ${ }_{\text {BSA }}$ in groups 1 and 2 was narrower than in controls $(P=.003$ and $P=.01$, respectively), LV posterior wall thickness ${ }_{\mathrm{BSA}}$ in group 1 was thicker than in the corresponding control $(P=.03)$, and septal thickness ${ }_{\text {BSA }}$ in group 1 was greater than in the matched control group $1(P=.01)$.

There were no significant differences between patients and controls with regard to indices of aortic valve and LV dimensions in diastole and systole (Table 2).

Table 3 shows preoperative and postoperative echocardiographic findings in patients. The aortoseptal angles in group 1 and the LVOT width BSA $_{\text {in }}$ group 1 were significantly wider.

Comparison of postoperative findings with controls showed a significant difference only in the aortoseptal angle in group 3 and LV posterior wall ${ }_{\mathrm{BSA}}$ and septal thickness ${ }_{\mathrm{BSA}}$ in group 1 (Table 4).

\section{Discussion}

Unlike previous studies, our study focused on children and adults without ventricular septal defects who were aged 4.7 to 42.5 years at operation during this survey period. Trans- thoracic and transesophageal echocardiography are useful in identifying LVOT abnormalities in subvalvar aortic stenosis. ${ }^{9,10,19-22}$ The progression of both the severity of obstruction and the degree of associated aortic regurgitation can be assessed by outflow tract Doppler pressure gradient. ${ }^{19}$

There was a significant difference between preoperative and postoperative values in aortoseptal angle (Figure 3, A, $B$ ) and LVOT width in patients up to 10 years of age. It is interesting that the aortoseptal angle was more acute in adults than children despite the higher range of preoperative echo gradient in the younger patients.

\section{Left Ventricular Outflow Tract Morphology}

In our study, patients with subaortic stenosis and intact ventricular septum had a significantly wider mitral-aortic separation compared with controls (Figure 1), confirming the findings previously reported in studies that mixed isolated lesions with associated ventricular septal defect and other complex malformations. 1,6,23 This feature was evident across all 3 age groups of our patients, although it was more evident in the younger patients (Table 2).

Mitral-aortic separation could be caused by transducer angulation, but Rosenquist and colleagues' anatomic study suggested that a prominent left-sided ventriculoinfundibular fold may contribute to the development of mitral-aortic valve separation. ${ }^{30}$ From our anatomic observations, the perceived separation can be attributable to "displacement" of the mitral hinge by left atrial myocardium overlapping the atrial aspect of the leaflet, not a muscular fold. Persistence of the left-sided ventriculoinfundibular fold is often seen in equine hearts but infrequently seen in human hearts with normal arrangement and connections of the chambers.

Kleinert and $\mathrm{Geva}^{2}$ reported a significantly steeper aortoseptal angle in patients with or without ventricular septal 
TABLE 2. Preoperative echocardiographic findings in patients and controls

\begin{tabular}{|c|c|c|c|c|}
\hline & Group 1 & Group 2 & Group 3 & $\begin{array}{c}\text { Groups } 1 / 2 / 3 \\
\text { Kruskal-Wallis } \\
P \text { value }\end{array}$ \\
\hline No. of controls & 9 & 8 & 4 & \\
\hline Age at operation (y) & $5(4.7-6.2)$ & $12(11.5-14.5)$ & $38.5(32.5-42.5)$ & \\
\hline Age of controls (y) & $5(3.7-6)$ & $12(11.5-14.5)$ & $38.5(33-42.5)$ & \\
\hline \multirow[t]{2}{*}{ Controls } & $4.4(3.9-5.2)$ & $2.5(2.3-3.1)$ & $4.5(4.5-4.5)$ & \\
\hline & $P=.003$ & $P=.024$ & $P=.8$ & \\
\hline \multicolumn{5}{|c|}{ Aortic valve annulus $\mathrm{BSA}_{\mathrm{BS}}$} \\
\hline Patients & $18.84(18.39-20.05)$ & $15(13-16.96)$ & $13.85(12.18-14.42)$ & $P<.001$ \\
\hline Controls & $19.10(17.15-19.85)$ & $13.9(13.6-15.32)$ & $14.3(14.3-14.3)$ & \\
\hline Controls & $P=.022$ & $P=.16$ & $P=.029$ & \\
\hline \multicolumn{5}{|c|}{ Aortic valve dextroposition } \\
\hline \multicolumn{5}{|c|}{ Patients/controls } \\
\hline Normal & $0(0 \%) / 0(0 \%)$ & $0(0 \%) / 0(0 \%)$ & $0(0 \%) / 0(0 \%)$ & \\
\hline Mild & $4(44 \%) / 2(22 \%)$ & $5(62 \%) / 4(50 \%)$ & $0(0 \%) / 1(20 \%)$ & \\
\hline Marked & $5(55 \%) / 3(33 \%)$ & $3(37 \%) / 0(0 \%)$ & $4(100 \%) / 3(60 \%)$ & \\
\hline \multicolumn{5}{|l|}{ AV-SAS distance $\mathrm{BSA}_{\mathrm{BS}}$} \\
\hline Patients & $6.42(5.73-8.34)$ & $4.81(4.14-5.76)$ & $4(3.71-5.17)$ & $P=.009$ \\
\hline \multicolumn{5}{|l|}{ LVOT width $_{\mathrm{BSA}}$} \\
\hline Patients & $8.68(7.78-10.40)$ & $7.68(7.45-8.68)$ & $8.06(6.72-8.12)$ & $P=.151$ \\
\hline Controls & $16.80(16.45-18.05)$ & $13.7(11.60-13.70)$ & $10.9(10.9-10.9)$ & \\
\hline \multirow[t]{2}{*}{ Controls } & $6.5(6.25-7.17)$ & $4.80(4.65-5.47)$ & $6(6.00-6.00)$ & \\
\hline & $P=.014$ & $P=.13$ & $P=.8$ & \\
\hline \multicolumn{5}{|c|}{ LV dimensions BSA $_{\text {(in end diastole) }}$} \\
\hline Patients & $43.42(41.32-45.95)$ & $30.25(29.26-34)$ & $27.42(24.73-27.43)$ & $P=.002$ \\
\hline \multirow[t]{2}{*}{ Controls } & 41.2 (39.37-44.35) & $29.9(28.1-31.77)$ & $27.2(27.2-27.2)$ & \\
\hline & $P=.62$ & $P=.25$ & $P=1$ & \\
\hline \multicolumn{5}{|c|}{ LV dimensions BSA $_{\text {(in end systole) }}$} \\
\hline Patients & $26.21(23.28-27.56)$ & $18.59(16.65-23.74)$ & $18.6(16.65-20.38)$ & $P=.041$ \\
\hline \multirow[t]{2}{*}{ Controls } & $27.4(25.17-32.77)$ & $20.5(18.7-20.72)$ & $17.7(17.7-17.7)$ & \\
\hline & $P=.188$ & $P=1$ & $P=1$ & \\
\hline
\end{tabular}

$L V$, Left ventricle; $B S A$, body surface area; $L V O T$, left ventricular outflow tract; $M V$ - $A V$, mitral valve-aortic valve; $A V$-SAS, aortic valve-subvalvar aortic stenosis.

defect. We report a similar finding in isolated subaortic stenosis (Table 2) and concur with their observation of exaggerated "aortic override." However, the term "override" is not used in the conventional sense because none of the hearts in our study had a subaortic ventricular septal defect for the valve to be overriding. Instead, we use the term "aortic valve dextroposition," and this feature was more marked in patients who were 21 years and older (group 3). Our study did not show a significant difference in aortic valve diameters between patients and controls. There was a significant increase in septal and left ventricular wall thickness $_{\mathrm{BSA}}$ in patients compared with controls, and this 
TABLE 3. $P$ values using the Wilcoxon signed-rank test comparing preoperative and postoperative echocardiographic findings in patients with subaortic stenosis and intact ventricular septum

\begin{tabular}{|c|c|c|c|}
\hline & Group 1 & Group 2 & Group 3 \\
\hline \multicolumn{4}{|c|}{ Aortoseptal angle (degree) } \\
\hline Preoperation & $125(114.25-130.50)$ & $118(113-128)$ & $110(105-110)$ \\
\hline \multirow{2}{*}{ Postoperation } & 135 (118.25-137.25) & $125(116.5-132)$ & $117(112-120)$ \\
\hline & $P=.016$ & $P=.62$ & $P=.25$ \\
\hline \multicolumn{4}{|l|}{ LVOT width $_{\text {BSA }}$} \\
\hline Preoperation & $8.68(7.78-10.4)$ & $7.68(7.45-8.6)$ & $8.06(6.72-8.12)$ \\
\hline \multirow[t]{2}{*}{ Postoperation } & $15.43(11.68-16.57)$ & $10.78(9.71-12.60)$ & $9.75(7.98-27.10)$ \\
\hline & $P=.008$ & $P=.12$ & $P=.25$ \\
\hline \multicolumn{4}{|c|}{ LV wall thickness ${ }_{\mathrm{BSA}}$} \\
\hline Preoperation & $8.36(7.3-9.5)$ & $6.47(5.98-7.12)$ & $6.94(6.13-7.81)$ \\
\hline \multirow[t]{2}{*}{ Postoperation } & $8.15(7.63-9.41)$ & $6.77(6.10-7.19)$ & $6.65(6.42-7.59)$ \\
\hline & $P=.94$ & $P=.62$ & $P=.75$ \\
\hline \multicolumn{4}{|c|}{ Septal thickness ${ }_{\mathrm{BSA}}$} \\
\hline Preoperation & $11.04(7.85-12.24)$ & $6.46(5.65-7.93)$ & $7(5.9-9.5)$ \\
\hline \multirow[t]{2}{*}{ Postoperation } & $11.08(7.62-12.47)$ & $6.14(5.49-6.22)$ & $7.01(6.46-9.87)$ \\
\hline & $P=.94$ & $P=.25$ & $P=.25$ \\
\hline \multicolumn{4}{|c|}{ LV dimensions BSA $_{\text {(in end diastole) }}$} \\
\hline Preoperation & $43.42(41.32-45.95)$ & $30.25(29.26-34)$ & $27.42(24.73-27.43)$ \\
\hline \multirow[t]{2}{*}{ Postoperation } & $42.04(40.54-45.33)$ & $24.8(21.94-28.32)$ & $23.65(21.12-26.68)$ \\
\hline & $P=.313$ & $P=1$ & $P=.5$ \\
\hline \multicolumn{4}{|c|}{ LV dimensions BSA $_{\text {(in end systole) }}$} \\
\hline Preoperation & $26.21(23.28-27.56)$ & $18.59(16.65-23.74)$ & $18.6(16.65-20.38)$ \\
\hline \multirow[t]{2}{*}{ Postoperation } & $28.75(25.67-32.47)$ & $16.67(13.89-16.95)$ & $13.89(12.28-16.28)$ \\
\hline & $P=.156$ & $P=.5$ & $P=.25$ \\
\hline
\end{tabular}

$L V O T$, Left ventricular outflow tract; $L V$, left ventricle; $B S A$, body surface area.

increase in thickness was more obvious in patients aged less than 10 years (group 1).

\section{Pathogenesis of Subaortic Stenosis and Turbulence}

The presence of ventricular septal defects may itself set the scene for turbulent flow in the LVOT and subsequent subaortic stenosis formation by a proliferative mechanism. ${ }^{14-16}$ By excluding ventricular septal defects from our series, we have focused on other possible contributing morphologies in the development of chronic flow disturbance in the LVOT and subvalvar aortic stenosis. Chronic flow disturbance and turbulent flow as a result of the abnormal geometry may be responsible for increased shear stress, abnormal proliferative response, and increased endothelial cell turnover in the sulbvalvar region that may be age dependent. ${ }^{6,14-16,24}$

\section{Aortic Regurgitation}

Aortic regurgitation is an important known association $^{3,10-12,17,25}$ (Table 1), and this is also demonstrated in our study. Multifactorial causes have been put forward for the development of aortic regurgitation in association with subvalvar aortic stenosis. ${ }^{3,10,12,17,18,25}$ For example, the distance between the aortic valve and the subaortic lesion (Table 2) may remodel flow through the valve.

\section{Timing of Operation and Recurrence}

Suggested mechanisms for recurrence after surgical resection of the lesion include residual tissues and/or proliferation. Even after complete removal of the protruding lesion, it is thought that the abnormal geometry of the LVOT remains. ${ }^{6}$ Our study suggests that the outflow tract is "remodeled" postoperatively in terms of aortoseptal angle and aortic valve dextroposition, especially in younger patients. If this alteration upstream from the lesion can normalize flow pattern, a potential risk of recurrence may be reduced. The significant enlargement of the width of the LVOT detected in the younger age group was not found in the oldest patients. There are 2 possible reasons for this: (1) Proportionally less tissue was removed in older patients compared with young patients. (2) The tract itself in older patients was intrinsically less narrow preoperatively; we were unable to find a significant difference in width of the outflow tract when we compared the oldest group with controls. Also, patients presenting at different ages for surgery are likely to have different degrees of abnormal geometry, with the more severe cases requiring earlier surgery.

Furthermore, young patients could have an adaptive mechanism to remodel their LVOT, and this mechanism may be lost in older patients. Comparison of our postoper- 
TABLE 4. $P$ values using the Mann-Whitney nonparametric test comparing controls and postoperative echocardiographic findings in patients with subaortic stenosis and intact ventricular septum

\begin{tabular}{|c|c|c|c|}
\hline & Group 1 & Group 2 & Group 3 \\
\hline \multicolumn{4}{|c|}{ Aortoseptal angle (degree) } \\
\hline Postoperation & $135(118.25-137.25)$ & $125(116.5-132)$ & $117(112-120)$ \\
\hline Controls & $\begin{array}{c}133(130.25-138.5) \\
P=.75\end{array}$ & $\begin{array}{c}128.5(126.5-131.5) \\
P=.81\end{array}$ & $\begin{array}{c}129(122.5-135) \\
P=.05\end{array}$ \\
\hline \multicolumn{4}{|l|}{ LVOT width ${ }_{\mathrm{BSA}}$} \\
\hline Postoperation & $15.43(11.68-16.57)$ & $10.78(9.71-12.60)$ & $9.75(7.98-27.10)$ \\
\hline Controls & $\begin{array}{c}16.8(16.45-18.05) \\
P=.17\end{array}$ & $\begin{array}{c}13.7(11.6-13.7) \\
P=.23\end{array}$ & $\begin{array}{c}10.9(10.9-10.9) \\
P=.8\end{array}$ \\
\hline \multicolumn{4}{|c|}{ LV wall thickness ${ }_{\mathrm{BSA}}$} \\
\hline Postoperation & $8.15(7.63-9.41)$ & $6.77(6.10-7.19)$ & $6.65(6.42-7.59)$ \\
\hline Controls & $\begin{array}{c}6.8(6.27-7.52) \\
P=.03\end{array}$ & $\begin{array}{c}6(5.47-6.52) \\
P=.4\end{array}$ & $\begin{array}{c}4.6(4.6-4.6) \\
P=.4\end{array}$ \\
\hline \multicolumn{4}{|c|}{ Septal thickness $\mathrm{BSA}$} \\
\hline Postoperation & $11.08(7.62-12.47)$ & $6.14(5.49-6.22)$ & $7.01(6.46-9.87)$ \\
\hline Controls & $\begin{array}{c}6.5(6.25-7.17) \\
P=.03\end{array}$ & $\begin{array}{c}4.8(4.65-5.47) \\
P=.11\end{array}$ & $\begin{array}{c}6(6.00-6.00) \\
P=.4\end{array}$ \\
\hline \multicolumn{4}{|c|}{ LV dimensions disA $_{\text {(in end diastole) }}$} \\
\hline Postoperation & $42.04(40.54-45.33)$ & $24.81(21.94-28.32)$ & $24.09(21.12-27.12)$ \\
\hline Controls & $\begin{array}{c}41.2(39.37-44.35) \\
P=.93\end{array}$ & $\begin{array}{c}29.9(28.1-31.77) \\
P=.2\end{array}$ & $\begin{array}{c}27.2(27.2-27.2) \\
P=.8\end{array}$ \\
\hline \multicolumn{4}{|c|}{ LV dimensions BSA $_{\text {(in end systole) }}$} \\
\hline Postoperation & $28.75(25.67-32.47)$ & $16.67(13.89-16.95)$ & $13.89(12.28-16.28)$ \\
\hline Controls & $\begin{array}{c}27.4(25.17-32.77) \\
P=.93\end{array}$ & $\begin{array}{c}20.5(18.7-20.72) \\
P=.1\end{array}$ & $\begin{array}{c}17.7(17.7-17.7) \\
P=.4\end{array}$ \\
\hline
\end{tabular}

$L V O T$, Left ventricular outflow tract; $L V$, left ventricle; $B S A$, body surface area.

ative data with controls illustrates apparent "normalization" of the aortoseptal angle occurring in the younger groups but not in the oldest group (Table 4). The different results between younger and older patients could also be explained by the fact that these hearts change from pressure-loaded ventricles because of subaortic stenosis into volume-overloaded ventricles as the aortic valves begin to be incompetent in the older age group. In the future, abnormal geometry could be addressed surgically to reduce the turbulence and potential for recurrence. An aortoseptal angle less than 130 degrees and mitral valve-aortic valve separation ${ }_{\text {BSA }}$ of more than 4.5 could be used as a predictive model for the development of subaortic stenosis. ${ }^{2}$ The pathophysiology of formation of abnormal geometry of acute aortoseptal angle and mitral-aortic valve separation needs to be better understood before investigators address the cellular and turbulent theories as possible mechanisms for subaortic stenosis development.

\section{Limitations}

This retrospective study of 21 patients and 21 controls was small, and there was no follow-up. The wide age range studied necessitated arbitrary division of the patients into the age groups. Postoperative echocardiography was performed within 1 month of surgery, and longer follow-up will determine whether the observed changes in the young remain stable with time. Further research is needed to validate these echocardiographic predictors in a larger prospective study.

\section{Conclusions}

The geometry of the LVOT in hearts with subaortic stenosis and intact ventricular septum is abnormal. Postoperatively there were changes in LVOT width and aortoseptal angle. Compared with controls, the aortoseptal angle does not "normalize" when surgery is performed in older patients, suggesting that the geometry may be "remodeled" postoperatively in younger patients, making it advantageous to perform surgery earlier.

\section{References}

1. Grech V. Incidence and management of subaortic stenosis in Malta. Pediatr Cardiol. 2001;22:431.

2. Kleinert S, Geva T. Echocardiographic morphometry and geometry of the left ventricular outflow tract in fixed subaortic stenosis. J Am Coll Cardiol. 1993;22:1501-8.

3. Newfeld EA, Muster AJ, Paul MH, Idriss FS, Riker WL. Discrete subvalvar aortic stenosis in childhood. Am J Cardiol. 1976;38(1):53-61.

4. Kelly DT, Wulfsberg E, Rowe RD. Discrete subaortic stenosis. Circulation. 1972;46:309-22.

5. Braunwald E, Goldblatt A, Aygen MM, Rockoff SD, Morrow AG. Congenital aortic stenosis. 1: clinical and haemodynamic findings in 100 
patients. 2: Surgical treatment and results of operation. Circulation. 1963;27:426-62.

6. Gewillig M, Daenen W, Dumoulin M, Van Der Hauwaert L. Rheologic genesis of discrete subvalvular aortic stenosis: a Doppler echocardiographic study. J Am Coll Cardiol. 1992;19:818-24.

7. Weyman AE, Feigenbaum H, Hurwitz RA, Girod DA, Dillon JC, Chang S. Cross-sectional echocardiography in evaluating patients with discrete subaortic stenosis. Am J Cardiol. 1976;37:358-65.

8. Fowles RE, Martin RP, Popp RL. Apparent asymmetric hypertrophy due to angled interventricular septum. Am J Cardiol. 1980;46:386-92.

9. Frommelt MA, Snider R, Bove EL, Lupinetti FM. Echocardiographic assessment of subvalvular aortic stenosis before and after operation. J Am Coll Cardiol. 1992;19:1018-23.

10. Choi JY, Sullivan ID. Fixed subaortic stenosis: anatomical spectrum and nature of progression. Br Heart J. 1991;65:280-6.

11. Freedom RM, Pelech A, Brand A, Vogel M, Olley PM, Smallhorn J, et al. The progressive nature of subaortic stenosis in congenital heart disease. Int J Cardiol. 1985;8:137-48.

12. Wright GB, Keane JF, Nadas AS, Bernhard WF, Castaneda AR. Fixed subaortic stenosis in the young: medical and surgical cause in 83 patients. Am J Cardiol. 1983;52:830-5.

13. Freedom RM. The long and the short of it: some thoughts about the fixed forms of left ventricular outflow tract obstruction. $J$ Am Coll Cardiol. 1997;30:1843-6.

14. Cape EG, Vanauker MD, Sigfusson G, Tacy TA, del Nido PJ. Potential role of mechanical shear stress in the etiology of pediatric heart disease: septal shear stress in subaortic stenosis. J Am Coll Cardiol. 1997;30:247-54.

15. Davis PF, Remuzzi A, Gordon EJ, Dewey CF Jr, Gimbrove MA. Turbulent fluid shear stress induces vascular endothelial cell turnover in vitro. Proc Natl Acad Sci U S A. 1986;83:2114-7.

16. Borrow KM, Glgov S. Discrete subvalvular aortic stenosis: is the presence of upstream complex blood flow disturbances an important pathogenic factor? J Am Coll Cardiol. 1992;19:825-7.
17. Shem-Tov A, Schneeweiss A, Motro M, Neufeld HN. Clinical presentation and natural history of mild discrete subaortic stenosis. Follow-up of 1-17 years. Circulation. 1982;66:509-12.

18. Oliver JM, Gonzalez A, Gallego P, Sánchez-Recalde A, Benito F, Mesa JM. Discrete subaortic stenosis in adults: increased prevalence and slow rate of progression of the obstruction and aortic regurgitation. J Am Coll Cardiol. 2001;38:835-42.

19. Morrow AG, Fort L, Roberts WC, Braunwald E. Discrete subaortic stenosis complicated by aortic valvular regurgitation. Clinical, hemodynamic, and pathologic studies and the results of operative treatment. Circulation. 1965;31:163-71.

20. Goodkin GM, Tunick PA, Kronzon I. Proximal isovelocity surface area (PISA) in the evaluation of fixed membranous subaortic stenosis. Echocardiography. 2002;19:157-9.

21. Agrawal GG, Nanda NC, Htay T, Dod HS, Gandhari SR. Live three-dimensional transthoracic echocardiographic identification of discrete subaortic membranous stenosis. Echocardiography. 2003; 20:617-9.

22. Bezold LI, Smith EO, Kelly K, Colan SD, Gauvreau K, Geva T. Development and validation of an echocardiographic model for predicting progression of discrete subaortic stenosis in children. Am J Cardiol. 1998;81:314-20

23. Rosenquist GC, Cark EB, McAllister HA, Bharati, Edward JE. Increased mitral-aortic separation in discrete subaortic stenosis. Circulation. 1979;60:70-4.

24. Ferrans VJ, Muna WFT, Jones M, Roberts WC. Ultrastructure of the fibrous ring in patients with discrete subaortic stenosis. Lab Invest. 1978;39:30-40.

25. Motro M, Schneeweiss A, Shem-Tov A, Benjamin P, Kaplinsky E, Hegesh J. Correlation of distance from subaortic membrane to base of the right aortic valve cusp and the development of aortic regurgitation in mild discrete subaortic stenosis. Am J Cardiol. 1989;64: 395-6. 